\title{
Umbilical Granuloma in an Eight Year Child
}

\section{George SM ${ }^{1}$}

${ }^{1}$ Dr. Susan Mary George, MBBS, MRCPCH, PhD. Dr Megh Bahadur Parajuli Community Hospital, Ilam, Nepal.

Address for correspondence:

Dr. Susan Mary George

E-mail: susanmarygeorge@hotmail.com

\section{How to cite}

George SM. Umbilical Granuloma in an Eight Year Child. J Nepal Paediatr Soc 2016;36(3):317-318.

doi: http://dx.doi.org/10.3126/jnps.v36i3.15486

\section{Introduction}

$D_{k n o}$ scharging lesions in the umbilical region are rare but well known in neonatal period. Omphalitis, umbilical granuloma, patent urachus and persistent vitelo-intestinal duct are some of the commonest causes. If such a lesion is found in an older child, a careful detailed history and examination of the lesion can give clue to the diagnosis. We present one such case of a rare case of umbilical granuloma.

\section{The Case}

An eight year old girl presented to the clinic in rural Nepal with discharging 'lump' on her abdominal wall since early in infancy, without any pain, discomfort or uneasiness. Discharge was waxing and waning periodically and was non-tender and discharged blood stained serous fluid that stained the clothes thus causing embarrassment. No history of discharge of urine or faecal content from this mass. Abdominal examination was unremarkable.

\section{Discussion}

Umbilical granuloma is a benign abnormality commonly seen in neonates. The differential diagnoses of patent vitelo-intestinal duct and patent urachus must be considered in cases such as this, and relevant investigations should be carried out ${ }^{1,2}$. Conservative management of umbilical granulomas in neonatal period includes moist dressing, prevention of friction and application of salt to encourage epithelialisation. Umbilical granulomas can be treated with cauterisation with topical silver nitrate application. Some may need surgical management- electrocautery, cryotherapy or ligature can be employed ${ }^{1,2,3}$. It is unusual to see umbilical granuloma in an older child. This patient was referred for surgical resection of the granuloma. 


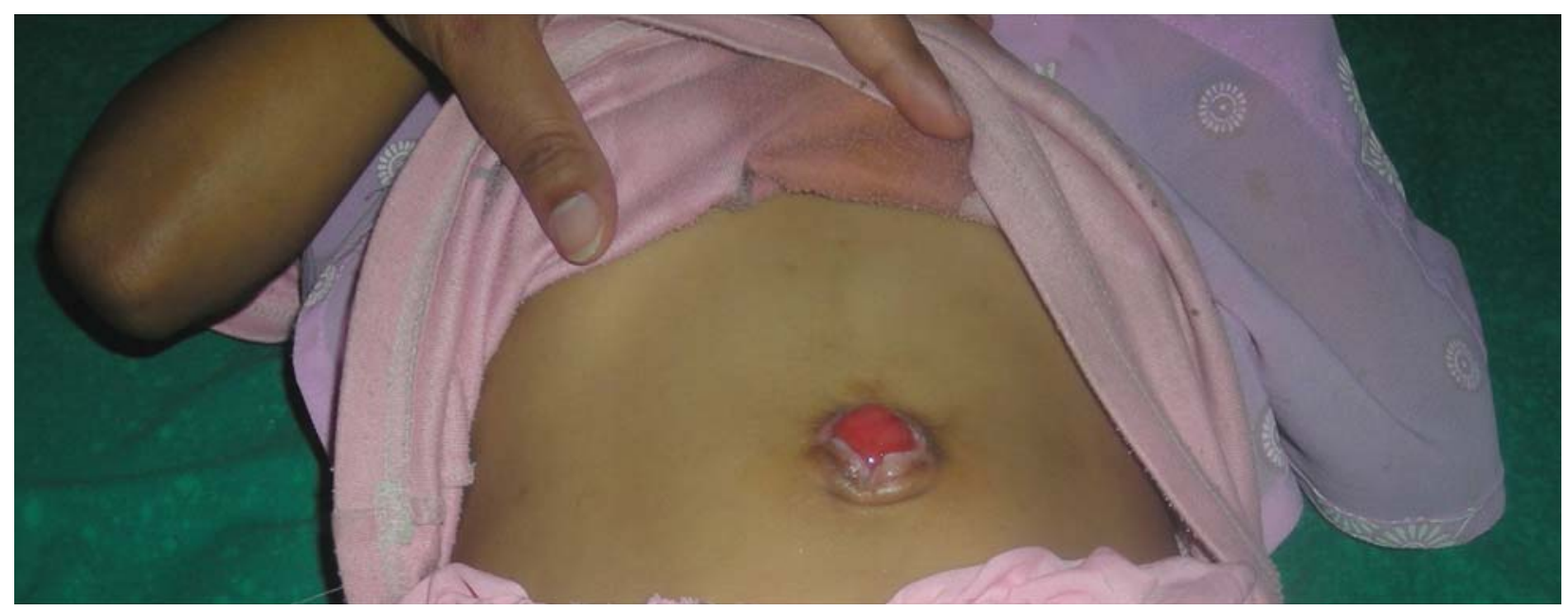

Image: Umbilical granuloma in a young child.

\section{References}

1. Alexander G, Walsh R, Nielsen A. Neonatal Umbilical Mass. West J Emerg Med 2013;14(2):163.

2. CampbellJ,BeasleySW,McMullinN, etal. Clinicaldiagnosis of umbilical swellings and discharges in children. Med $J$ Aust. 1986;145:450-453.

3. Disorders of the umbilicus in infants and children: $A$ consensus statement of the Canadian Association of Paediatric Surgeons. Paediatr Child Health Vol 6 No 6 July/August 2001. 